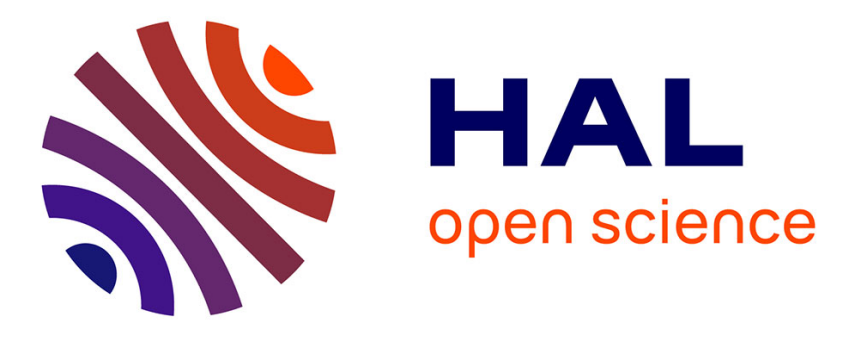

\title{
Narrow Linewidth Excitonic Emission in Organic-Inorganic Lead Iodide Perovskite Single Crystals
}

Hiba Diab, Gaelle Trippe-Allard, Ferdinand Lédée, Khaoula Jemli, Christèle Vilar, Guillaume Bouchez, Vincent L.R Jacques, Antonio Tejeda, Jacky Even, Jean-sébastien Lauret, et al.

\section{To cite this version:}

Hiba Diab, Gaelle Trippe-Allard, Ferdinand Lédée, Khaoula Jemli, Christèle Vilar, et al.. Narrow Linewidth Excitonic Emission in Organic-Inorganic Lead Iodide Perovskite Single Crystals. Journal of Physical Chemistry Letters, 2016, 7 (24), pp.5093-5100. 10.1021/acs.jpclett.6b02261 . hal-01405439

\author{
HAL Id: hal-01405439 \\ https://hal.science/hal-01405439
}

Submitted on 4 May 2017

HAL is a multi-disciplinary open access archive for the deposit and dissemination of scientific research documents, whether they are published or not. The documents may come from teaching and research institutions in France or abroad, or from public or private research centers.
L'archive ouverte pluridisciplinaire HAL, est destinée au dépôt et à la diffusion de documents scientifiques de niveau recherche, publiés ou non, émanant des établissements d'enseignement et de recherche français ou étrangers, des laboratoires publics ou privés. 


\section{Letter}

\section{Narrow Linewidth Excitonic Emission in Organic- Inorganic Lead lodide Perovskite Single Crystals}

Hiba Diab, Gaelle Trippe-Allard, Ferdinand Lédée, Khaoula Jemli, Christèle Vilar, Guillaume Bouchez, Vincent L.R Jacques, Antonio Tejeda, Jacky Even, Jean-Sébastien Lauret, Emmanuelle Deleporte, and Damien Garrot J. Phys. Chem. Lett., Just Accepted Manuscript • DOI: 10.1021/acs.jpclett.6b02261 • Publication Date (Web): 25 Nov 2016

Downloaded from http://pubs.acs.org on November 29, 2016

\section{Just Accepted}

"Just Accepted" manuscripts have been peer-reviewed and accepted for publication. They are posted online prior to technical editing, formatting for publication and author proofing. The American Chemical Society provides "Just Accepted" as a free service to the research community to expedite the dissemination of scientific material as soon as possible after acceptance. "Just Accepted" manuscripts appear in full in PDF format accompanied by an HTML abstract. "Just Accepted" manuscripts have been fully peer reviewed, but should not be considered the official version of record. They are accessible to all readers and citable by the Digital Object Identifier (DOI®). "Just Accepted" is an optional service offered to authors. Therefore, the "Just Accepted" Web site may not include all articles that will be published in the journal. After a manuscript is technically edited and formatted, it will be removed from the "Just Accepted" Web site and published as an ASAP article. Note that technical editing may introduce minor changes to the manuscript text and/or graphics which could affect content, and all legal disclaimers and ethical guidelines that apply to the journal pertain. ACS cannot be held responsible for errors or consequences arising from the use of information contained in these "Just Accepted" manuscripts. 


\section{Abstract}

Hybrid perovskite thin films have demonstrated impressive performance for solar energy conversion and optoelectronic applications. However, further progress will benefit from a better knowledge of the intrinsic photophysics of materials. Here, the temperature-dependent emission properties of $\mathrm{CH}_{3} \mathrm{NH}_{3} \mathrm{PbI}_{3}$ single crystals are investigated and compared to those of thin polycrystalline films by means of steady-state and time-resolved photoluminescence spectroscopy. Single crystals photoluminescence present a sharp excitonic emission at high energy, with Full Width at Half Maximum of only $5 \mathrm{meV}$, assigned to free excitonic recombination. We highlight a strong thermal broadening of the free excitonic emission, due to exciton-LOphonons coupling. The emission turned to be very short-lived with a sub-nanosecond dynamics, mainly induced by the fast trapping of the excitons. The free excitonic emission is completely absent of the thin films spectra, which are dominated by trap states band.

\section{Graphical TOC Entry}

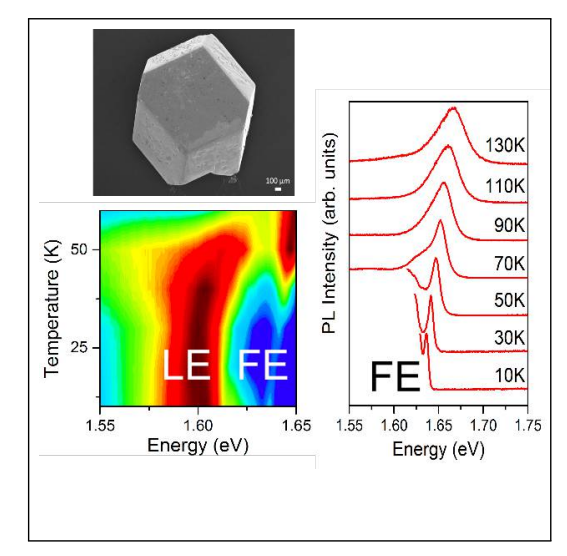




\section{Main}

Recently, a great attention has been devoted to three-dimensional hybrid organic perovskites (HOP) due to their remarkable results as lightharvesting material for low-cost solar cells. In particular, a breakthrough has been achieved with solar energy conversion reaching $22 \%$ using hybrid perovskite as active material. ${ }^{1-3}$ Moreover, HOP demonstrate impressive emission properties which make them an attractive material for light emitting diodes and laser applications. $^{4-6}$

A better understanding of the photophysical properties underlying these performances is important for further device improvements. The study of the photoluminescence (PL) of semiconductors at low temperature has proved to be an efficient tool not only to understand the material physics but also to assess the crystalline quality, the nature of defects, and impurities. Studies on the emission of $\mathrm{CH}_{3} \mathrm{NH}_{3} \mathrm{PbI}_{3}$ at low temperature are relatively scarce and the majority concerns polycrystalline thin films. ${ }^{7-10}$ Yet, the grain structure of the perovskites thin films have a strong influence on their optical and electronic properties and then on the device performances. ${ }^{11,12}$ For instance, the band gap position, the carrier diffusion, the recombination and the excitonic effects depend on the degree of crystallinity of the sample. ${ }^{11,13-17}$ Hence, the study of bulk single crystals appears necessary in order to measure the intrinsic characteristics of HOP. Although bulk single crystals are less suitable for the realization of large area solar cells than thin films, they should serve as a reference material.

Among the fundamental properties of HOP, the nature of the photoexcited states, excitons or free charges, is an important question to understand the remarkable performance of $\mathrm{CH}_{3} \mathrm{NH}_{3} \mathrm{PbI}_{3}$ in solar cells and optoelectronic devices. ${ }^{7,8,18-21}$ Recent studies suggest that free carriers are the dominant species at room temperature, while excitons prevail in the low temperature orthorhombic phase. ${ }^{22-24}$ At low temperature, excitons could generally be observed in bulk semiconductors through the emission of sharp lines with Full Width at Half Maximum
(FWHM) of ca. $1 \mathrm{meV} .{ }^{25}$

However, previous studies on both films and single crystals report multi-component, broad emissions, with a FWHM of several tens of meV, presenting a weak broadening with temperature. ${ }^{8-10,26-28}$ In comparison, a recent study of $\mathrm{CH}_{3} \mathrm{NH}_{3} \mathrm{PbBr}_{3}$ single crystals unambiguously led to the observation of sharp, WannierMott excitonic emission. ${ }^{29}$ These obervations suggest that the previously reported PL emission of $\mathrm{CH}_{3} \mathrm{NH}_{3} \mathrm{PbI}_{3}$ at low temperature was dominated by trap states. ${ }^{30}$ This short review of the literature clearly indicates that the low temperature photoluminescence of $\mathrm{CH}_{3} \mathrm{NH}_{3} \mathrm{PbI}_{3}$ has still to be thoroughly investigated on a single crystal exhibiting very narrow emission lines, in order to definitively identify the intrinsic emission at low temperature.

In this study, we performed temperaturedependent Steady-State and Time-Resolved Photoluminescence on high quality $\mathrm{CH}_{3} \mathrm{NH}_{3} \mathrm{PbI}_{3}$ single crystals. Single crystals present a narrow emission line (FWHM $\sim 5 \mathrm{meV}$ at $10 \mathrm{~K}$ ) on the high energy side of the PL spectrum. This emission is absent of the PL spectra of thin films. From the position, line-shape and power dependence, this line is attributed to the free exciton. Analysis of the thermal evolution of this emission demonstrates a strong homogeneous broadening in the orthorhombic phase in strong contrast with previous studies. A large Exciton-LO-Phonon coupling explains this behaviour in good agreement with recent studies on polarons in HOP. Besides, this emission presents a non-exponential, fast recombination dynamic, with sub-nanosecond leading time. On the other hand, a broad multicomponent line is observed on the low energy side of the spectrum, and is assigned to trap states. In comparison, thin polycrystalline films present only the trap state emission, likely formed at the surfaces/interfaces of materials.

Figure 1(a) shows a SEM view of the morphology of the samples. Despite some local inhomogeneities, single crystals present clean and relatively flat surfaces that allows to probe the emission properties of large monocrystalline domains of $\mathrm{CH}_{3} \mathrm{NH}_{3} \mathrm{PbI}_{3}$ (see Figure $1(\mathrm{~b})$ ).

Figure 1(c) displays the PL map of a 
(a)

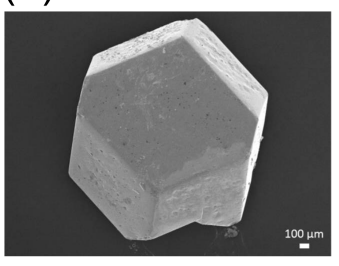

(b)

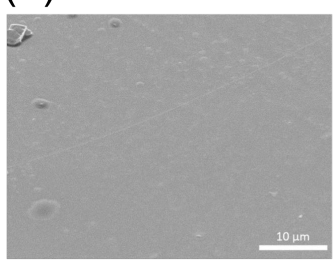

(c)

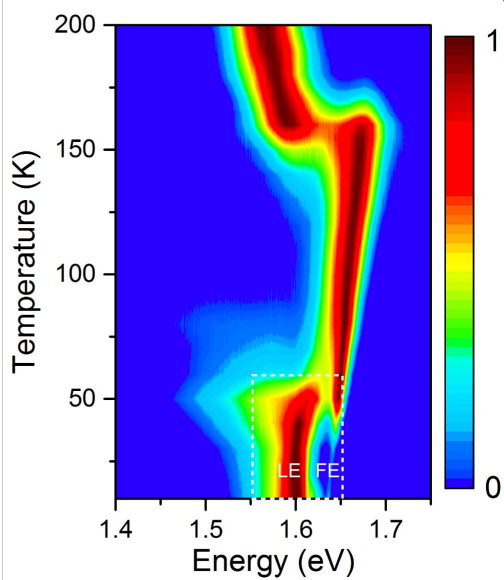

(d)

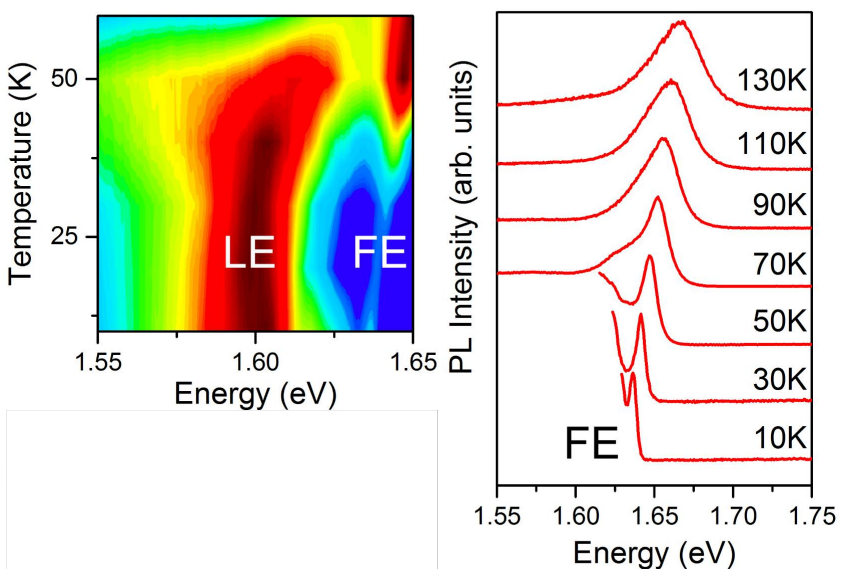

Figure 1: (a) Top view SEM image of a mm-sized $\mathrm{CH}_{3} \mathrm{NH}_{3} \mathrm{PbI}_{3}$ crystal. (b) Higher resolution SEM image of the surface of the crystal. (c) PL map as a function of temperature of a single $\mathrm{CH}_{3} \mathrm{NH}_{3} \mathrm{PbI}_{3}$ crystal with an enlarged view of the FE and LE band below 60K (d) Few PL spectra at different temperatures with a zoom on the FE emission.

$\mathrm{CH}_{3} \mathrm{NH}_{3} \mathrm{PbI}_{3}$ single crystal between $10 \mathrm{~K}$ and $200 \mathrm{~K}$. The emission at $200 \mathrm{~K}$ is composed of a single band. It presents a blueshift in the range of $170 \mathrm{~K}$ and $150 \mathrm{~K}$, which is related to the tetragonal-orthorhombic phase transition that induces a band gap energy switching of $\sim 100 \mathrm{meV} \cdot{ }^{9,26}$ Outside the thermal range of the phase transition, the PL band shows a redshift with decreasing temperature, which indicates a reduction of the band gap with lattice contraction. This behavior is in contrast with typical semiconductors, such as $\mathrm{Si}$ or GaAs, ${ }^{31,32}$ and is connected to the antibonding nature of the states of the top of the valence band. ${ }^{33,34}$ This unusual trend is also observed in lead chalcogenides. ${ }^{35,36}$ Below $150 \mathrm{~K}$, in the orthorhombic phase, the crystal shows a welldefined PL line at high energy (see Figure 1(c) and (d)). The high energy sharp emission, centered at $\sim 1.638 \mathrm{eV}$ with a FWHM of only $5 \mathrm{meV}$ at $10 \mathrm{~K}$, presents a large temperatureinduced broadening between $10 \mathrm{~K}$ and $160 \mathrm{~K}$. It is completely absent of thin films PL spectra (as will be discussed in the next section) and of the PL spectra reported in the single previous study on the low temperature emission of $\mathrm{CH}_{3} \mathrm{NH}_{3} \mathrm{PbI}_{3}$ single crystals. ${ }^{26}$ The energy position of the band is very close to the low temperature excitonic absorption. ${ }^{7,22}$

The narrow linewidth observed could be com- pared to the typical linewidth of excitonic peaks in high quality bulk inorganic semiconductors, which is approximately $1 \mathrm{meV}$ at $\sim 10 \mathrm{~K} \cdot{ }^{37-40}$ We note that narrow free excitonic emissions of ca. $5 \mathrm{meV}$ have also been reported in $\mathrm{CsPbX}_{3}$ $(\mathrm{X}=\mathrm{Cl}, \mathrm{Br})$ and $\mathrm{PbI}_{2}{ }^{41,42}$ and very recently in $\mathrm{CH}_{3} \mathrm{NH}_{3} \mathrm{PbBr}_{3}$ but is observed here for the first time for $\mathrm{CH}_{3} \mathrm{NH}_{3} \mathrm{PbI}_{3}$. By comparison, the FWHM previously reported at low temperature for $\mathrm{CH}_{3} \mathrm{NH}_{3} \mathrm{PbI}_{3}$ remains larger than $80 \mathrm{meV}$ on thin films ${ }^{30}$ and $30 \mathrm{meV}$ on single crystals, ${ }^{26}$ likely because the reported emission originated from extrinsic trap states. Besides, the observation of such a narrow linewidth at low temperature is an indication of a weak inhomogeneous broadening and of the good crystallinity of our samples.

To further analyze the nature of the sharp PL emission, experiments as a function of the excitation power density has been performed. Figure S3 shows the power density dependence of the PL integrated intensity of the FE emission at $10 \mathrm{~K}$. The intensity could be fitted by a power law of the form $I^{\lambda}$ with $\lambda=1.17$. In direct band gap semiconductor, $\lambda$ should be comprised between 1 and 2 for free and bound excitonic transition. ${ }^{43}$ The near band edge position of the high energy peak suggests that the emission could be assigned to Free Excitonic (FE) recombination. We remark however that 
we could not completely exclude the possibility of an exciton bound to a very shallow trap state. However, if bound excitons induce sharp emission line at low temperature, they generally present no thermal broadening due to the lack of kinetic energy. ${ }^{44}$ Finally, crystals show broad and multicomponent emission on the low energy (LE) side of the spectra. Its nature will be discussed in the next section.

Unlike thin films emission, ${ }^{30}$ the well-defined PL spectra of crystals allow to study for the first time the temperature evolution of the free exciton of $\mathrm{CH}_{3} \mathrm{NH}_{3} \mathrm{PbI}_{3}$ down to very low temperatures. Figure 2 displays the FWHM of the FE PL as a function of temperature. A large broadening with temperature is observed, from $5 \mathrm{meV}$ at $10 \mathrm{~K}$ to $40 \mathrm{meV}$ at $160 \mathrm{~K}$. This broadening is quite stronger than in typical semiconductors in the same thermal range. For example, in the inorganic direct band gap semiconductor GaAs, between $10 \mathrm{~K}$ and $150 \mathrm{~K}$, the linewidth increases very slightly of approximately a factor 2 (from approximately 1.5 to $3 \mathrm{meV}$ ). Hence, the thermal evolution of the FE linewidth suggests an important homogenous broadening due to electron-phonon coupling. Note that a strong phonon coupling in $\mathrm{CH}_{3} \mathrm{NH}_{3} \mathrm{PbI}_{3}$ has been hypothesized to explain the large homogenous broadening observed at room temperature. ${ }^{6}$ The following relation has been proposed to describe the evolution of exciton linewidth with temperature in semiconductors: ${ }^{45}$

$$
\begin{aligned}
\Gamma(T) & =\Gamma_{0}+\Gamma_{a c}+\Gamma_{L O} \\
& =\Gamma_{0}+\gamma_{a c} T+\frac{\gamma_{L O}}{e^{\frac{E_{L O} O}{k_{B} T}}-1}
\end{aligned}
$$

$\Gamma_{0}$ is the temperature independent inhomogenous broadening, the terms $\Gamma_{a c}$ and $\Gamma_{L O}$ arise from the scattering by the acoustic phonons and the optical phonons respectively with the coupling strength $\gamma_{a c}$ and $\gamma_{L O} . \quad E_{L O}$ is the energy of the optical phonons. The broadening mechanism is dominated by the coupling to LO-phonons and the fitting procedure returns a negligible value for the acoustic phonon term, which could not in consequence be de-

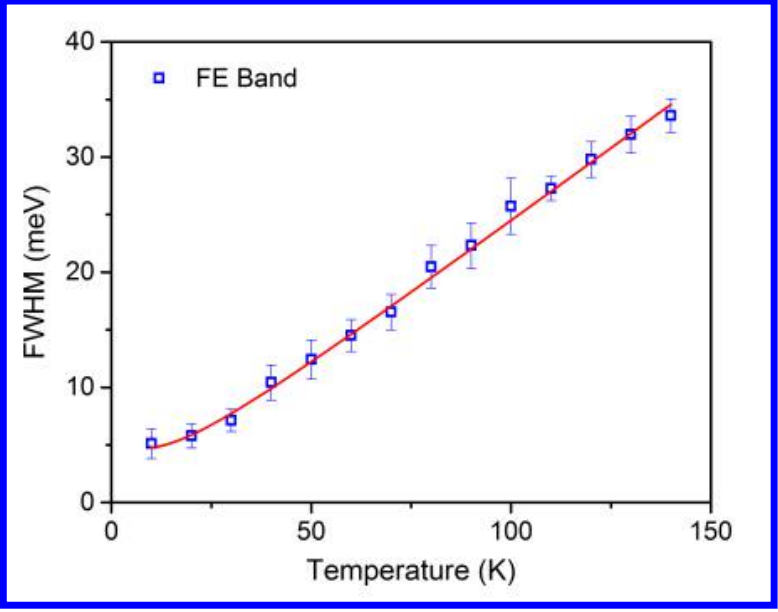

Figure 2: FWHM of the FE line as a function of temperature (blue squares). Error bar reflects the standard deviation of repeated measures. The red curve is a fit of the data with $\Gamma(T)=$ $\Gamma_{0}+\Gamma_{L O}(T)$ (see the text)

termined and has been fixed to zero in the following. The fit leads to the following values $\Gamma_{0}=4.6 \pm 0.5 \mathrm{meV}, \gamma_{L O}=12 \pm 2 \mathrm{meV}$ and $E_{L O}=4.2 \pm 0.8 \mathrm{meV}$. The vibrational properties of HOP are not well established but experimental and theoretical progresses have recently been made. ${ }^{46-49}$ For instance, A.D. Wright and coworkers have reported very recently experiments on thin films of $\mathrm{HC}\left(\mathrm{NH}_{2}\right)_{2} \mathrm{PbX}_{3}, \mathrm{X}=\mathrm{I}, \mathrm{Br}$ and $\mathrm{CH}_{3} \mathrm{NH}_{3} \mathrm{PbX}_{3}, \mathrm{X}=\mathrm{I}, \mathrm{Br}$. They report a negligible interaction with acoustic phonons and the prevalence of Fröhlich coupling to LOphonons, mostly supported with theoretical considerations. However due to the presence of very broad low energy contributions in the orthorhombic phase of $\mathrm{CH}_{3} \mathrm{NH}_{3} \mathrm{PbX}_{3}$ compounds, the authors were only able to perform extrapolation of the FWHM measured in the tetragonal phase. They estimate $\gamma_{L O}$ to $40 \mathrm{meV}$ for $\mathrm{CH}_{3} \mathrm{NH}_{3} \mathrm{PbI}_{3}$, using the LO phonon energy of $11.5 \mathrm{meV}$ deduced for $\mathrm{CH}_{3} \mathrm{HC}\left(\mathrm{NH}_{2}\right)_{2} \mathrm{PbI}_{3} \cdot{ }^{30}$ Our present study on single crystal shows that the $\Gamma_{L O}$ and $\mathrm{E}_{L O}$ have to be strongly revised. The value of the effective LO-phonon mode extracted from the fit is in much better agreement with a recent study based on vibrational spectroscopy and calculation by Leguy and coworkers. ${ }^{49}$ The authors have identified optical phonon modes in hybrid perovskite at very 
low energy compared to typical semiconductors, with in particular, a lowest optical mode activated from $4 \mathrm{meV}$ in $\mathrm{CH}_{3} \mathrm{NH}_{3} \mathrm{PbI}_{3}$. More, Soufiani et al. ${ }^{20}$ have also proposed an estimation of an effective polaronic LO-phonon energy of $4.1 \mathrm{meV}$ based on permittivity measurements. Recent calculations and symmetry analysis show that the main contribution to the mobility of both electrons and holes in $\mathrm{CH}_{3} \mathrm{NH}_{3} \mathrm{PbI}_{3}$ arises from coupling with polar optical phonons. ${ }^{48}$ For polar semiconductors, such as GaAs, Frölich interaction to LOphonons is generally responsible for the majority of the broadening at room temperature. This interaction is expected to be important in HOP due to the polar lead-iodide bonds and the ionic character of this material. The quantitative knowledge of the low energy LO-phonon excitations is thus very important since carrier mobility models based on the Frölich interaction exhibit power-law dependence on the LOphonon energy. ${ }^{50}$

In the following, the connection between the FE and LE lines is investigated. First, the thermal evolution of both FE and LE bands PL intensities is discussed. Figure 3(a) represents the PL integrated intensity of the free excitonic emission (blue squares) and of the LE band (red squares). The PL intensity of the FE peak presents a non-monotonous thermal evolution: it increases first with temperature and reaches a maximum at $50 \mathrm{~K}$ and then decreases. This behavior is associated with the quenching of the LE defect emissions (red dot). This unambiguously shows that both contributions are connected. The thermal quenching of the PL integrated intensity could be described with the familiar equation:

$$
I_{P L}=\frac{I_{0}}{1+A \exp \frac{-E_{a}}{k_{B} T}}
$$

Where $I_{0}$ is the PL intensity at $0 \mathrm{~K} . E_{a}$ is the activation energy of a non-radiative process and $k_{B}$ is the Boltzmann constant. We estimate an activation energy of approximately $\mathrm{E}_{a}=19.9 \pm 0.6 \mathrm{meV}$ for the quenching of the low energy band, associated to the exciton detrapping (solid red line on Figure 3(a)). This value corresponds roughly to the FE-LE energy separation. Above 50K, the FE emission quenches in turn with an activation energy of $\mathrm{E}_{a}=28.4 \pm 0.6 \mathrm{meV}$. The latter process is mainly connected to the dissociation of the exciton and the energy gives a rough estimation of the binding energy of the free exciton in the low temperature orthorhombic phase. However, we note that apart from the influence of the LE emitting states, additional non-radiative, thermal quenching processes may also exist and are not taking into account here. This estimation of the binding energy in the low temperature phase is in good agreement with recent measurements based on the fitting of the thin films absorption spectrum with Elliott's formulas (15-30 meV). ${ }^{20,23,27,51}$ Nicholas and coworkers use a more direct method relying on magnetoabsorption spectroscopy of thin films and report a binding energy of $16 \mathrm{meV}$ in the orthorhombic phase. ${ }^{22}$ We remark that the majority of studies on the excitonic binding energy focused on thin films properties. However, Petrozza and coworkers have observed that the excitonic resonance depends on the crystallinity of the material and suggest that the degree of order-disorder of the organic cation may have an impact on exciton binding energy. ${ }^{13,15}$ Hence, polycrystalline thin films, with microscale grain size, and large bulk monocrystalline domains may present different excitonic properties. ${ }^{29}$ Study of the absorption spectra of single crystals under high magnetic field would be fruitful to clarify this point.

We performed Time-Resolved Photoluminescence (TR-PL) measurements to get more insight on the recombination mechanisms. Figure $3(\mathrm{~b})$ presents the PL dynamics decay at $10 \mathrm{~K}$ of the FE and LE emissions. The decay of the FE presents a very fast, non-exponential dynamics. To be quantitative, we define a characteristic lifetime of the decay $\tau$ such as $I(\tau)=\frac{I(0)}{e}$. With this definition, the characteristic lifetime of the decay is approximately 150 ps for the FE emission at 10K. For comparison, fast decay with leading time of the order of several tens of ps has been reported for the free excitonic emission of single crystals of $\mathrm{CsPbX}_{3}(\mathrm{X}=\mathrm{Cl}, \mathrm{Br}) .{ }^{42,52} \mathrm{~A}$ non-exponential de- 


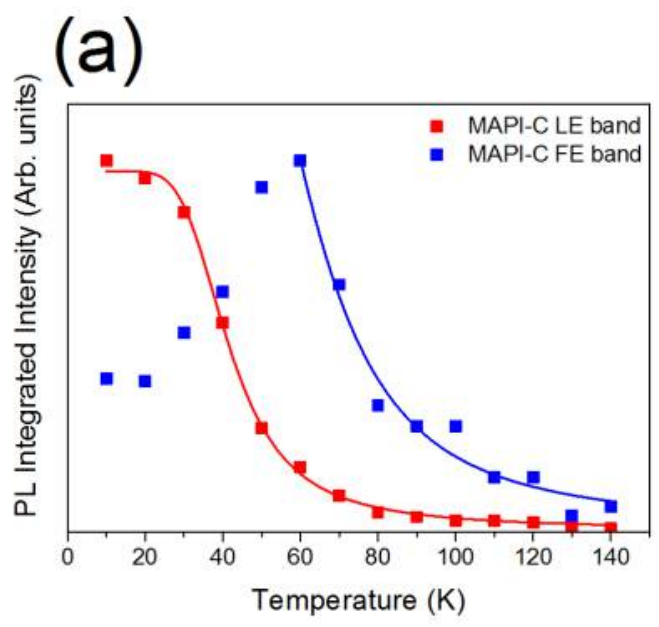

(b)

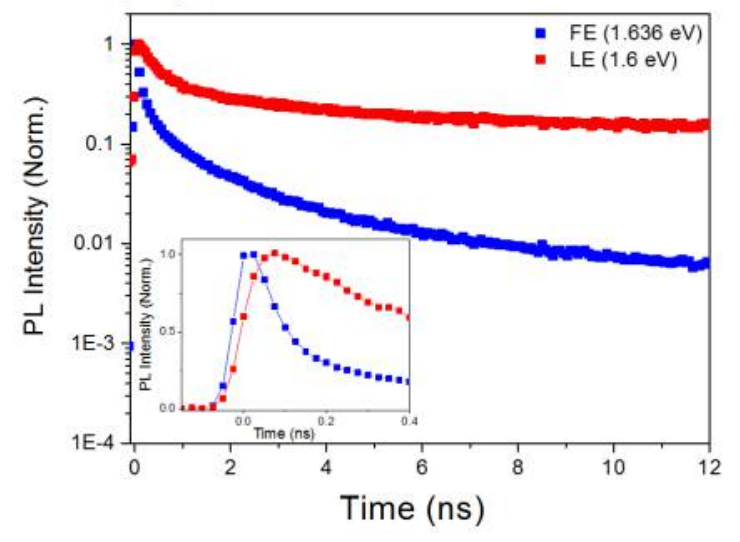

Figure 3: (a) PL integrated intensity as a function of temperature for the FE line (blue squares) and the $\mathrm{LE}_{1}$ line (red squares). (b) Time-Resolved PL in logarithmic scale of the FE line (blue) and $\mathrm{LE}_{1}$ line (red) at 10K. Inset: Time-resolved PL of the FE line (blue) and $\mathrm{LE}_{1}$ line (red) at $10 \mathrm{~K}$, on a sub-nanosecond timescale. Note that the scale is linear.

cay with an approximately 100 ps characteristic time has also been reported for single crystal of $\mathrm{PbI}_{2} \cdot{ }^{53}$ This fast, non-exponential recombination results from efficient capture processes by the trap states. Inset of Figure $3 \mathrm{~b}$ supports this interpretation since it shows a rising time on the LE emission dynamics that corresponds to the fast decay of the FE line. Moreover, a fast sub-nanosecond component in the PL of $\mathrm{CH}_{3} \mathrm{NH}_{3} \mathrm{PbI}_{3}$ thin films has been recently reported at room temperature, under weak irradiation, attributed to a rapid relaxation of the carriers to defects states. ${ }^{54}$ Finally, the LE band at $10 \mathrm{~K}$ has a ns timescale decay and nonexponential dynamics. We note that the estimation of the slower component is limited by the time range of our measurement.

In order to enrich the discussion, the direct comparison with the emission properties of standard thin-films of $\mathrm{CH}_{3} \mathrm{NH}_{3} \mathrm{PbI}_{3}$ is very useful. Figure 4(a) displays the PL map of a thinfilm of $\mathrm{CH}_{3} \mathrm{NH}_{3} \mathrm{PbI}_{3}$, recorded with the same CW excitation than the crystal PL map. The PL emission of thin films shares some common features with single crystal emission (see Figure 1), but nevertheless, shows striking differences, in particular below $150 \mathrm{~K}$ in the orthorhombic phase.

Thin films present a broad multicomponent emission with a FWHM of several tens of meV at $10 \mathrm{~K}$, which is nearly temperature independent between $10 \mathrm{~K}$ and $100 \mathrm{~K}$. The direct comparison, on Figure 4(b), between crystals and thin films demonstrates that the emission of thin films is very similar (energy position and width) to the LE bands of the crystal. In particular, at 10K, the LE emission bands, positioned at $\sim 1.60 \mathrm{eV}$ and with a FWHM of ca. $60 \mathrm{meV}$ superimpose very well. In addition, the PL decay of the LE band presents similar nanosecond dynamics on both films and crystals (Figure S6). However, the high energy FE emission is completely absent of the thin films PL, despite the fact that a clear excitonic resonance is visible on the thin film absorption spectra (Figure S7). Hence, thin films PL is dominated by trap states emission. The latter could be decomposed, as temperature is raised, in two bands denoted $\mathrm{LE}_{1}$ and $\mathrm{LE}_{2}$. The $\mathrm{LE}_{2}$ emission is quite stronger on thin films and seems to extend in the high temperature tetragonal phase (peak $\mathrm{T})$. This observation suggests that this band is connected to the inclusions of the tetragonal phase in the low temperature orthorhombic phase, due to an incomplete phase transition in agreement with previous study on thin films. ${ }^{8-10}$ Diffuse scattering and disorder was observed in X-ray diffraction below the tetragonal to orthorombic phase transition for the previous investigation on $\mathrm{CH}_{3} \mathrm{NH}_{3} \mathrm{PbI}_{3}$ single crys- 
tals, but the luminescence of tetragonal phase inclusions was not mentioned. ${ }^{26}$ However, we observe that the $\mathrm{LE}_{2}$ emission, though weak between $60 \mathrm{~K}$ and $130 \mathrm{~K}$, is still present on crystals spectra, indicating that tetragonal inclusions may exists also for the crystalline form. Measurements at different points of the crystals have been performed and for specific positions a strong $\mathrm{LE}_{2}$ component have been observed. Note that the as-grown crystals present surface imperfections ( Figure1(a)). Our measurements suggest that small tetragonal phase domains exist at low temperature at the surface of single crystals, possibly due to local surface imperfections that act as nucleation centers. Crystal imperfections might help to stabilize the high temperature phase through mechanical strain. ${ }^{55}$ Recently, these inclusions have been reported for $\mathrm{CH}_{3} \mathrm{NH}_{3} \mathrm{PbI}_{3}$ microplate single crystals through electron diffraction and $\mathrm{PL}$ measurements. ${ }^{56}$ Previously reported spectra of $\mathrm{CH}_{3} \mathrm{NH}_{3} \mathrm{PbI}_{3}$ single crystals correspond to the present $\mathrm{LE}_{1}$ and $\mathrm{LE}_{2}$ emissions. ${ }^{26} \mathrm{The}_{1} \mathrm{LE}_{1}$ peak was attributed to a FE emission on a basis of a TR-PL lifetime measurement, whereas a bound state emission with a triplet state character was proposed for the $\mathrm{LE}_{2}$ peak exhibiting a millisecond dynamics. The narrow FE emission peak of the present study was not observed.

To get further insight in the nature of the trap states, we study the power dependence of the PL spectra at $10 \mathrm{~K}$ and $50 \mathrm{~K}$ (Figure 5). The sharp FE emission clearly dominates the spectra at high fluence and maintains its position and width.

The $\mathrm{LE}_{2}$ band presents a relative decrease at higher laser density, compatible with a saturation behavior, and shifts toward higher energy. Due to this blue-shift under high fluence, Donor Acceptor Pair (DAP) recombination in $\mathrm{CH}_{3} \mathrm{NH}_{3} \mathrm{PbI}_{3}$ have been suggested by Kong et al. ${ }^{10}$ Similar observations have been reported in $\mathrm{CH}_{3} \mathrm{NH}_{3} \mathrm{PbBr}_{3}$ crystals. ${ }^{29}$ Alternatively, Li et al. have proposed that this blue-shift is connected to the accumulation of carriers inside the small tetragonal phase inclusions, inducing a band filling effect. ${ }^{56}$ We focus now on the properties of the $\mathrm{LE}_{1}$ band. We observe that the peak is slightly redshifted compare to the FE

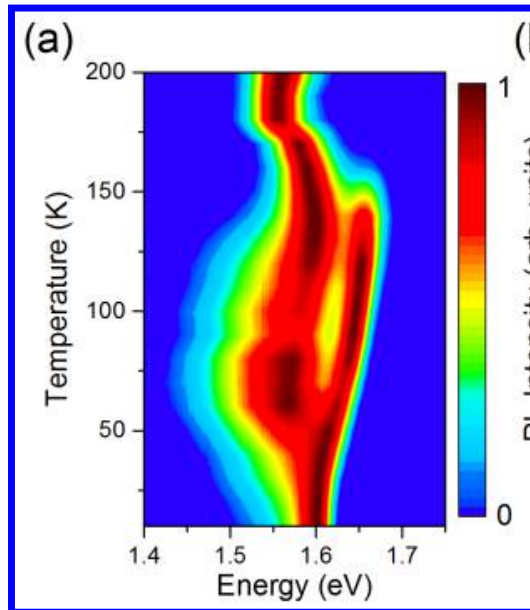

(b)

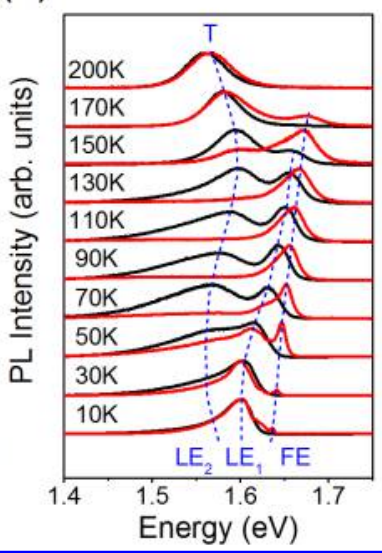

Figure 4: (a) PL map as a function of temperature of a $\mathrm{CH}_{3} \mathrm{NH}_{3} \mathrm{PbI}_{3}$ film. (b) Comparison at different temperature between normalised $\mathrm{PL}$ spectra of $\mathrm{CH}_{3} \mathrm{NH}_{3} \mathrm{PbI}_{3}$ crystal (red) and film (black).

peak and follow the thermal shift of the latter between $10 \mathrm{~K}$ and $150 \mathrm{~K}$ and it disappears at the orthorhombic-tetragonal phase transition. Besides, the $\mathrm{LE}_{1}$ contribution seems to maintain its position under high fluence excitation. At $50 \mathrm{~K}$, this component is clearly visible at 1.619 $\mathrm{eV}$. On thin films, even at the highest fluence, the high energy FE peak is still indistinguishable (Figure S8) and the $\mathrm{LE}_{1}$ band dominates the emission.

Only the comparison with the single crystal $\mathrm{PL}$ allows us to assign the $\mathrm{LE}_{1}$ emission to trap states. More precisely, this peak could be assigned to bound excitons. However, we remark that the $L_{1}$ peak is very broad compare to the single crystals FE emission. Excitons bound to shallow donnors or aceptors produce very sharp lines. A possible origin for the $\mathrm{LE}_{1}$ band may arise from polaronic effect. In the polaron framework, strong coupling of an exciton with the lattice vibration could lead to its immobilization (ie self-trapping). Self-trapping induces broad, Stokes-shifted emissions and occurs in pico or sub-picosecond timescale. ${ }^{57}$ The phenomena has been observed in alkali-halide and lead-halide ${ }^{57,58}$ and may account for white-light emission in 2D HOP. ${ }^{59,60}$

Different authors suggest that the reorientation of the MA cation and its associated dipole, is connected to the formation of polaronic 
states. ${ }^{61,62}$ The strong exciton-LO-Phonon coupling observed in this study is consistent with the formation of self-trapped excitons. Importantly, the self-trapping could be intrinsic or extrinsic. In the latter case, the process is mediated by the presence of disorder and/or defects. ${ }^{63}$ Hence, the self-trapping of excitons may likely be formed at the surface or interfaces between grains, where reorientation of the terminal MA cations and deformation of the crystal structure in general is easier, as also proposed by Wu et al. ${ }^{61}$

In thin polycrystalline films, with relatively small micrometric grain size, we suppose a fast diffusion and self-trapping of excitons at the interfaces, which completely prevent the observation of a free excitonic emission even at high laser power density. In crystals, a large fraction of the excitons could diffuse and recombine in the volume of the material. Such an interpretation is well supported both by the data showing the quenching of the LE bands with the concomitant rise of the FE band and by the TR-PL data.

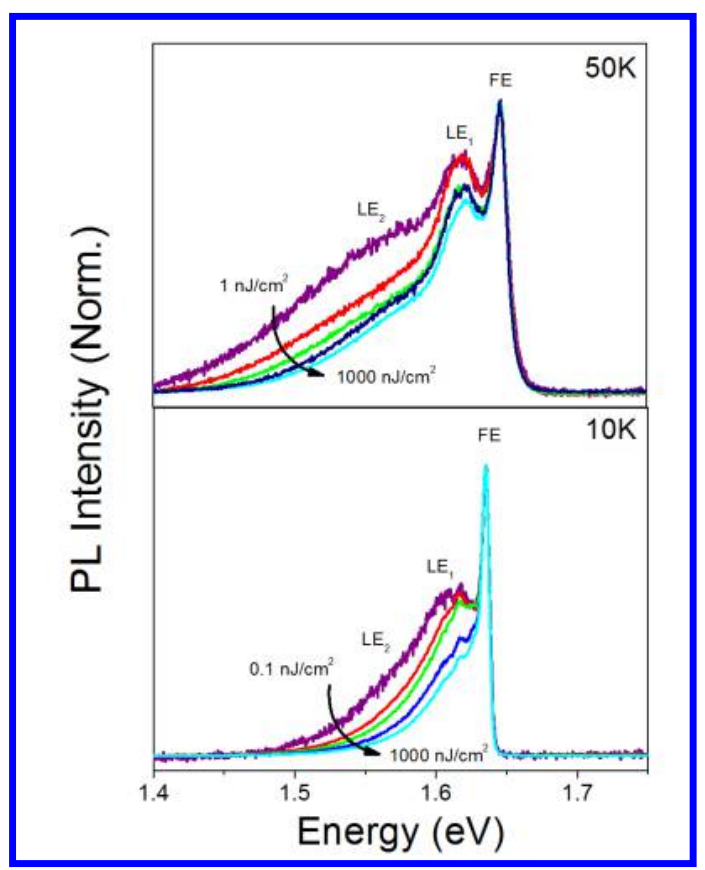

Figure 5: Power dependence of the PL of $\mathrm{CH}_{3} \mathrm{NH}_{3} \mathrm{PbI}_{3}$ single crystal at $10 \mathrm{~K}$ and $50 \mathrm{~K}$.

The surface/interface origin of the trap states could also explain the important similarity between the LE emission band of films and crystals: due to the large absorption coefficient of
$\mathrm{CH}_{3} \mathrm{NH}_{3} \mathrm{PbI}_{3}\left(\alpha \approx 10^{5} \mathrm{~cm}^{-1}\right.$ for an excitation wavelength of $400 \mathrm{~nm}),{ }^{64}$ the penetration depth of the light is approximately of $100 \mathrm{~nm}$, which means that we are still sensitive to the surface states, despite the large size of the crystal. As previously mentioned, crystals present locally some inhomogeneities and roughness and we have observed relative variations of the free excitonic emission compared to the LE band intensity at some points of the crystal surface. However, crystals, unlike thin films, present also large areas with clean and smooth surfaces giving access to the intrinsic emission properties of $\mathrm{CH}_{3} \mathrm{NH}_{3} \mathrm{PbI}_{3}$.

In summary, free excitonic emission has been observed on $\mathrm{CH}_{3} \mathrm{NH}_{3} \mathrm{PbI}_{3}$ single crystal at low temperature. The free exciton emission spectra is a sharp line, with a FWHM of $5 \mathrm{meV}$ at 10K. From the analysis of the thermal evolution of the free excitonic line, we demonstrate a strong homogenous broadening of the emission connected to Fröhlich interaction with LOphonons. The free exciton emission presents a non-exponential decay with sub-nanosecond characteristic time, dominated by the rapid relaxation to trap states. In comparison, the emission of $\mathrm{CH}_{3} \mathrm{NH}_{3} \mathrm{PbI}_{3}$ thin films at low temperature is dominated by trap states and the free excitonic emission is never observed even under high fluence excitation. The low energy bands are very similar at low temperature on thin films and crystal in term of position, width, fluence-dependence and recombination dynamics and are likely connected to the formation of trap states at the surface/interfaces of the material. Our results lead to a deeper understanding of the photophysics of 3D HOP and highlight the importance of studying bulk single crystals in order to access to the intrinsic properties of 3D HOP. Besides, our findings reinforce the idea that low temperature PL spectroscopy is a relevant tool to assess the crystalline quality in $3 \mathrm{D} \mathrm{HOP}$.

Acknowledgement This work has received funding from the European Union's Horizon 2020 research and innovation programme under the grant agreement No 687008. The information and views set out in this paper are those of 
the author(s) and do not necessarily reflect the official opinion of the European Union. Neither the European Union institutions and bodies nor any person acting on their behalf may be held responsible for the use which may be made of the information contained herein. J.S. Lauret is a junior member of the Institut Universitaire de France.

\section{Supporting Information Avail- able}

The following files are available free of charge.

Experimental methods, Thin film SEM view, XRD pattern, Fluence-dependent PL, Data fitting, Thin film PL decay.

\section{References}

(1) Saliba, M.; Matsui, T.; Seo, J.-Y.; Domanski, K.; Correa-Baena, J.-P.; Nazeeruddin, M. K.; Zakeeruddin, S. M.; Tress, W.; Abate, A.; Hagfeldt, A. et al. Cesiumcontaining Triple Cation Perovskite Solar Cells: Improved Stability, Reproducibility and High Efficiency. Enerau Environ. Sci. 2016, 9, 1989-1997.

(2) Yang, W. S.; Noh, J. H.; Jeon, N. J.; Kim, Y. C.; Ryu, S.; Seo, J.; Seok, S. I. I. High-performance Photovoltaic Perovskite Layers Fabricated Through Intramolecular Exchange. Science 2015, 348, 1234-1237.

(3) NREL Chart. (Accessed November 2016); http://www.nrel.gov/ncpv/images/ efficiency_chart.jpg.

(4) Xing, G.; Mathews, N.; Lim, S. S.; Yantara, N.; Liu, X.; Sabba, D.; Gratzel, M.; Mhaisalkar, S.; Sum, T. C. Low-temperature Solution-processed Wavelength-tunable Perovskites for Lasing. Nat.Mater. 2014, 13, 476-480.

(5) Deschler, F.; Price, M.; Pathak, S.; Klintberg, L. E.; Jarausch, D.-D.; Higler, R.;
Huettner, S.; Leijtens, T.; Stranks, S. D.; Snaith, H. J. et al. High Photoluminescence Efficiency and Optically Pumped Lasing in Solution-Processed Mixed Halide Perovskite Semiconductors. $L$ Phus. Chem.Lett. 2014, 5, 1421-1426.

(6) Wehrenfennig, C.; Liu, M.; Snaith, H. J.; Johnston, M. B.; Herz, L. M. Homogeneous Emission Line Broadening in the Organo Lead Halide Perovskite $\mathrm{CH}_{3} \mathrm{NH}_{3} \mathrm{PbI}_{3}-x \mathrm{Cl}_{x}$. J. Phus. Chem. Lett. 2014, 5, 1300-1306.

(7) D’Innocenzo, V.; Grancini, G.; Alcocer, M. J. P.; Kandada, A. R. S.; Stranks, S. D.; Lee, M. M.; Lanzani, G.; Snaith, H. J.; Petrozza, A. Excitons Versus Free Charges in Organo-lead Trihalide Perovskites. Nat. Commun. 2014, 5, 3586 .

(8) Wu, K.; Bera, A.; Ma, C.; Du, Y.; Yang, Y.; Li, L.; Wu, T. Temperaturedependent Excitonic Photoluminescence of Hybrid Organometal Halide Perovskite Films. Phys. Chem. Chem. Phys. 2014, 16, 22476-22481.

(9) Wehrenfennig, C.; Liu, M.; Snaith, H. J.; Johnston, M. B.; Herz, L. M.; Wehrenfennig, C.; Liu, M.; Snaith, H. J. Charge Carrier Recombination Channels in the Lowtemperature Phase of Organic-inorganic Lead Halide Perovskite Thin Films. APL Mater. 2014, 2, 081513.

(10) Kong, W.; Ye, Z.; Qi, Z.; Zhang, B.; Wang, M.; Rahimi-Iman, A.; Wu, H. Characterization of an Abnormal Photoluminescence Behavior upon Crystal-phase Transition of Perovskite $\mathrm{CH}_{3} \mathrm{NH}_{3} \mathrm{PbI}_{3}$. Phys. Chem. Chem. Phys. 2015, 17, 16405-16411.

(11) de Quilettes, D. W.; Vorpahl, S. M.; Stranks, S. D.; Nagaoka, H.; Eperon, G. E.; Ziffer, M. E.; Snaith, H. J.; Ginger, D. S. Impact of Microstructure on Local Carrier Lifetime in Perovskite Solar Cells. Science 2015, 348, 683-686. 
(12) Nie, W.; Tsai, H.; Asadpour, R.; Blancon, J.-C.; Neukirch, A. J.; Gupta, G.; Crochet, J. J.; Chhowalla, M.; Tretiak, S.; Alam, M. A. et al. Highefficiency Solution-processed Perovskite Solar Cells with Millimeter-scale Grains. Science 2015, 347, 522-525.

(13) Grancini, G.; Marras, S.; Prato, M.; Giannini, C.; Quarti, C.; De Angelis, F.; De Bastiani, M.; Eperon, G. E.; Snaith, H. J.; Manna, L. et al. The Impact of the Crystallization Processes on the Structural and Optical Properties of Hybrid Perovskite Films for Photovoltaics. L. Phus. Chem. Lett, 2014, 5, 3836-3842.

(14) De Bastiani, M.; D’Innocenzo, V.; Stranks, S. D.; Snaith, H. J.; Petrozza, A. Role of the Crystallization Substrate on the Photoluminescence Properties of Organo-lead Mixed Halides Perovskites. APL Mater. 2014, 2, 81509.

(15) D'Innocenzo, V.; Srimath Kandada, A. R.; De Bastiani, M.; Gandini, M.; Petrozza, A. Tuning the Light Emission Properties by Band Gap Engineering in Hybrid Lead-halide Perovskite. J. Am. Chem. Soc. 2014, 136, 17730-17733.

(16) Grancini, G.; Srimath Kandada, A. R.; Frost, J. M.; Barker, A. J.; De Bastiani, M.; Gandini, M.; Marras, S.; Lanzani, G.; Walsh, A.; Petrozza, A. Role of Microstructure in the Electron-hole Interaction of Hybrid Lead Halide Perovskites. Nat. Photonics 2015, 7, 695-702.

(17) Yamada, Y.; Yamada, T.; Phuong, L. Q.; Maruyama, N.; Nishimura, H.; Wakamiya, A.; Murata, Y.; Kanemitsu, Y. Dynamic Optical Properties of $\mathrm{CH}_{3} \mathrm{NH}_{3} \mathrm{PbI}_{3}$ Single Crystals as Revealed by One- and Two-photon Excited Photolumines-cence Measurements. J. Am. Chem. Soc. 2015, 137, 10456-10459.

(18) Yamada, Y.; Nakamura, T.; Endo, M.; Wakamiya, A.; Kanemitsu, Y. Photocarrier Recombination Dynamics in Per- ovskite $\mathrm{CH}_{3} \mathrm{NH}_{3} \mathrm{PbI}_{3}$ for Solar Cell Applications. J. Am. Chem. Soc. 2014, 136, 11610-11613.

(19) Sheng, C.; Zhang, C.; Zhai, Y.; Mielczarek, K.; Wang, W.; Ma, W.; Zakhidov, A.; Vardeny, Z. V. Exciton versus Free Carrier Photogeneration in Organometal Trihalide Perovskites Probed by Broadband Ultrafast Polarization Memory Dynamics. Phus. Rev. Lett. 2015, 114, 116601.

(20) Soufiani, A. M.; Huang, F.; Reece, P.; Sheng, R.; Ho-Baillie, A.; Green, M. A. Polaronic Exciton Binding Energy in Iodide and Bromide Organic-inorganic Lead Halide Perovskites. Anol. Phus. Lett. 2015, 10\%, 231902.

(21) Zheng, K.; Zhu, Q.; Abdellah, M.; Messing, M. E.; Zhang, W.; Generalov, A. V.; Niu, Y.; Ribaud, L.; Canton, S. E.; Pullerits, T. Exciton Binding Energy and the Nature of Emissive States in Organometal Halide Perovskites. J. Phys. Chem. Lett. 2015, 6, 2969-2975.

(22) Miyata, A.; Mitioglu, A.; Plochocka, P.; Portugall, O.; Wang, J. T.-W.; Stranks, S. D.; Snaith, H. J.; Nicholas, R. J. Direct Measurement of the Exciton Binding Energy and Effective Masses for Charge Carriers in Organicinorganic Tri-halide Perovskites. Nat. Phus. 2015, 11, 582-587.

(23) Even, J.; Pedesseau, L.; Katan, C. Analysis of Multivalley and Multibandgap Absorption and Enhancement of Free Carriers Related to Exciton Screening in Hybrid Perovskites. L.Phus. Chem.C 2014, 118, 11566-11572.

(24) Ziffer, M. E.; Mohammed, J. C.; Ginger, D. S. Electroabsorption Spectroscopy Measurements of the Exciton Binding Energy, Electron-hole Reduced Effective Mass, and Band Gap in the Perovskite $\mathrm{CH}_{3} \mathrm{NH}_{3} \mathrm{PbI}_{3}$. ACS Photonics 2016, 3, 1060-1068. 
(25) Klingshirn, C. F. Semiconductor Ontics; Graduate Texts in Physics; Springer Berlin Heidelberg: Berlin, Heidelberg, 2012.

(26) Fang, H.-H.; Raissa, R.; Abdu-Aguye, M.; Adjokatse, S.; Blake, G. R.; Even, J.; Loi, M. A. Photophysics of OrganicInorganic Hybrid Lead Iodide Perovskite Single Crystals. Adv. Funct. Mater. 2015, 25, 2378-2385.

(27) Yamada, Y.; Nakamura, T.; Endo, M.; Wakamiya, A.; Kanemitsu, Y. Photoelectronic Responses in Solution-Processed Perovskite $\mathrm{CH}_{3} \mathrm{NH}_{3} \mathrm{PbI}_{3}$ Solar Cells Studied by Photoluminescence and Photoabsorption Spectroscopy. IEEE J. Photovoltaics 2014, 5, 401-405.

(28) Tahara, H.; Endo, M.; Wakamiya, A.; Kanemitsu, Y. Experimental Evidence of Localized Shallow States in Orthorhombic Phase of $\mathrm{CH}_{3} \mathrm{NH}_{3} \mathrm{PbI}_{3}$ Perovskite Thin Films Revealed by Photocurrent Beat Spectroscopy. J. Phus. Chem. C 2016, 120, 5347-5352.

(29) Tilchin, J.; Dirin, D. N.; Maikov, G. I.; Sashchiuk, A.; Kovalenko, M. V.; Lifshitz, E. Hydrogen-like Wannier-Mott Excitons in Single Crystal of Methylammonium Lead Bromide Perovskite. ACS Nano 2016, 10, 6363-6371.

(30) Wright, A. D.; Verdi, C.; Milot, R. L.; Eperon, G. E.; Pérez-Osorio, M. A.; Snaith, H. J.; Giustino, F.; Johnston, M. B.; Herz, L. M. Electron-phonon Coupling in Hybrid Lead Halide Perovskites. Nat. Commun. 2016, \%, 0.

(31) Wei, S.-H.; Zunger, A. Predicted Bandgap Pressure Coefficients of All Diamond and Zinc-blende Semiconductors: Chemical Trends. Physical Review B 1999, 60, 5404-5411.

(32) Varshni, Y. Temperature Dependence of the Energy Gap in Semiconductors. Phusica 1967, 34, 149-154.
(33) Frost, J. M.; Butler, K. T.; Brivio, F.; Hendon, C. H.; van Schilfgaarde, M.; Walsh, A. Atomistic Origins of HighPerformance in Hybrid Halide Perovskite Solar Cells. Nano Letters 2014, 14, 25842590 .

(34) Even, J.; Pedesseau, L.; Katan, C.; Kepenekian, M.; Lauret, J.-S.; Sapori, D.; Deleporte, E. Solid-State Physics Perspective on Hybrid Perovskite Semiconductors. J.Phus. Chem.C 2015, 119, 1016110177.

(35) Svane, A.; Christensen, N. E.; Cardona, M.; Chantis, A. N.; van Schilfgaarde, M.; Kotani, T. Quasiparticle Selfconsistent $\mathrm{Gw}$ Calculations for Pbs, Pbse, and Pbte: Band Structure and Pressure Coefficients. Phusical Review B 2010, 81, 245120 .

(36) Kigel, A.; Brumer, M.; Maikov, G. I.; Sashchiuk, A.; Lifshitz, E. Thermally Activated Photoluminescence in Lead Selenide Colloidal Quantum Dots. Small 2009, 5, 1675-1681.

(37) Kudrawiec, R.; Rudziński, M.; Serafinczuk, J.; Zając, M.; Misiewicz, J. Photoreflectance Study of Exciton Energies and Linewidths for Homoepitaxial and Heteroepitaxial Gan Layers. I.Apol. Phus. 2009, 105, 093541.

(38) Teke, A.; Özgür, Ü.; Doğan, S.; Gu, X.; Morkoç, H.; Nemeth, B.; Nause, J.; Everitt, H. O. Excitonic Fine Structure and Recombination Dynamics in Singlecrystalline ZnO. Phus. Rev. B 2004, 70, 195207.

(39) Hamby, D. W.; Lucca, D. A.; Klopfstein, M. J.; Cantwell, G. Temperature Dependent Exciton Photoluminescence of Bulk ZnO. L. Anol. Phus. 2003, 93, 3214.

(40) Lee, J.; Koteles, E. S.; Vassell, M. O. Luminescence Linewidths of Excitons in GaAs Quantum Wells below 150 K. Phys. Rev. B 1986, 33, 5512-5516. 
(41) Fröhlich, D.; Heidrich, K.; Künzel, H.; Trendel, G.; Treusch, J. Cesiumtrihalogen-plumbates a New Class of Ionic Semiconductors. J. Lumin. 1979, 18-19, 385-388.

(42) Nikl, M.; Mihokova, E.; Nitsch, K.; Polak, K.; Rodova, M.; Dusek, M.; Pazzi, G.; Fabeni, P.; Salvini, L.; Gurioli, M. Photoluminescence and Decay Kinetics of $\mathrm{CsPbCl}_{3}$ Single Crystals. Chem. Phys. Lett. 1994, 220, 14-18.

(43) Schmidt, T.; Lischka, K.; Zulehner, W. Excitation-power Dependence of the Nearband-edge Photoluminescence of Semiconductors. Phus. Rev. B 1992, 45, 89898994.

(44) Pelant, Y.; Valanta, J. Luminescence Spectroscony of Semiconductors; Oxford University Press, 2012.

(45) Rudin, S.; Reinecke, T. L.; Segall, B. Temperature-dependent Exciton Linewidths In Semiconductors. Phus. Rev.B 1990, 42, 11218-11231.

(46) Quarti, C.; Grancini, G.; Mosconi, E.; Bruno, P.; Ball, J. M.; Lee, M. M.; Snaith, H. J.; Petrozza, A.; De Angelis, F. The Raman Spectrum of the $\mathrm{CH}_{3} \mathrm{NH}_{3} \mathrm{Pbl}_{3}$ Hybrid Perovskite: Interplay of Theory and Experiment. Journal Of Phusical Chemistru Letters 2014, 5, 279-284.

(47) Even, J.; Carignano, M.; Katan, C. Molecular Disorder and Translation/rotation Coupling in the Plastic Crystal Phase of Hybrid Perovskites. Nanoscale 2016, 8, 6222-36.

(48) Even, J.; Paofai, S.; Bourges, P.; Letoublon, A.; Cordier, S.; Durand, O.; Katan, C. Carrier Scattering Processes and Low Energy Phonon Spectroscopy in Hybrid Perovskites Crystals. 2016, 97430M.
(49) Leguy, A. M. A.; Goñi, A. R.; Frost, J. M.; Skelton, J.; Brivio, F.; RodríguezMartínez, X.; Weber, O. J.; Pallipurath, A.; Alonso, M. I.; CampoyQuiles, M. et al. Dynamic Disorder, Phonon Lifetimes, and the Assignment of Modes to the Vibrational Spectra of Methylammonium Lead Halide Perovskites. Phus. Chem. Chem. Phus. 2016, 18, 27051-27066.

(50) Seeger, K. Semiconductor Physics An Introduction; Springer Berlin Heidelberg: Berlin, Heidelberg, 1984.

(51) Saba, M.; Cadelano, M.; Marongiu, D.; Chen, F.; Sarritzu, V.; Sestu, N.; Figus, C.; Aresti, M.; Piras, R.; Lehmann, A. G. et al. Correlated Electron-hole Plasma in Organometal Perovskites. Nat. Commun. 2014, 5, 5049.

(52) Nitsch, K.; Hamplová, V.; Nikl, M.; Polák, K.; Rodová, M. Lead Bromide and Ternary Alkali Lead Bromide Single Crystals - Growth and Emission Properties. Chem. Phus. Lett. 1996, 258, 518-522.

(53) Makino, T.; Watanabe, M.; Hayashi, T.; Ashida, M. Time-resolved Luminescence of Exciton Polaritons in $\mathrm{PbI}_{2}$. Phys. Rev. B 1998, 57, 3714-3717.

(54) Yamada, Y.; Yamada, T.; Shimazaki, A.; Wakamiya, A.; Kanemitsu, Y. Interfacial Charge-Carrier Trapping in $\mathrm{CH}_{3} \mathrm{NH}_{3} \mathrm{PbI}_{3}-$ Based Heterolayered Structures Revealed by Time-Resolved Photoluminescence Spectroscopy. J. Phus. Chem. Lett, 2016, 7, 1972-1977.

(55) Ong, K. P.; Goh, T. W.; Xu, Q.; Huan, A. Mechanical Origin of the Structural Phase Transition in Methylammonium Lead Iodide $\mathrm{CH}_{3} \mathrm{NH}_{3} \mathrm{PbI}_{3}$. J. Phys. Chem. Lett. 2015, 6, 681-685.

(56) Li, D.; Wang, G.; Cheng, H.-C.; Chen, C.Y.; Wu, H.; Liu, Y.; Huang, Y.; Duan, X. Size-dependent Phase Transition 
in Methylammonium Lead Iodide Perovskite Microplate Crystals. Nat. Commun. 2016, \%, 11330.

(57) Williams, R. T.; Song, K. S. The Selftrapped Exciton. L. Phus. Chem. Solids 1990, 51, 679-716.

(58) Plekhanov, V. Lead Halides: Electronic Properties and Applications. Proa. Mater Sci. 2004, 49, 787-886.

(59) Dohner, E. R.; Hoke, E. T.; Karunadasa, H. I. Self-Assembly of Broadband White-Light Emitters. J. Am. Chem. Soc. 2014, 136, 1718-1721.

(60) Yangui, A.; Garrot, D.; Lauret, J. S.; Lusson, A.; Bouchez, G.; Deleporte, E.; Pillet, S.; Bendeif, E. E.; Castro, M.; Triki, S. et al. Optical Investigation of Broadband White-Light Emission in SelfAssembled Organic-Inorganic Perovskite $\left(\mathrm{C}_{6} \mathrm{H}_{11} \mathrm{NH}_{3}\right)_{2} \mathrm{PbBr}_{4}$. J. Phys. Chem. C 2015, 119, 23638-23647.

(61) Wu, X.; Trinh, M. T.; Niesner, D.; Zhu, H.; Norman, Z.; Owen, J. S.; Yaffe, O.; Kudisch, B. J.; Zhu, X. Trap States in Lead Iodide Perovskites. J. Am. Chem. Soc. 2015, 137, 2089-2096.

(62) Neukirch, A. J.; Nie, W.; Blancon, J.C.; Appavoo, K.; Tsai, H.; Sfeir, M. Y.; Katan, C.; Pedesseau, L.; Even, J.; Crochet, J. J. et al. Polaron Stabilization by Cooperative Lattice Distortion and Cation Rotations in Hybrid Perovskite Materials. Nano Lett. 2016, 16, 38093816 .

(63) Stoneham, A. M.; Gavartin, J.; Shluger, A. L.; Kimmel, A. V.; Ramo, D. M.; Rønnow, H. M.; Aeppli, G.; Renner, C. Trapping, Self-trapping and the Polaron Family. J. Phus. Condens. Matter 2007, 19, 255208.

(64) Green, M. A.; Jiang, Y.; Mahboubi Soufiani, A.; Ho-Baillie, A. W.-Y. Optical Properties of Photovoltaic Organic-
Inorganic Lead Halide Perovskites. $L$ Phus. Chem.Lett, 2015, 6, 4774-4785. 